\title{
PENGEMBANGAN KAPASITAS RELAWAN DI PMI CABANG CIBINONG, BOGOR
}

\author{
Oleh: \\ Ashari Utomo Putra, Soni Ahmad Nulhaqim, Rudi Saprudin Darwis.
}

Email:

Ashariutp@gmail.com

\begin{abstract}
ABSTRAK Dewasa ini pengembangan kapasitas merupakan bagian yang penting di dalam berbagai aspek kehidupan. Dalam kehidupan sehari-hari pengembangan kapasitas dilaksanakan dengan pendidikan baik secara formal maupun informal. Pengembangan kapasitas relawan merupakan suatu proses yang dapat meningkatkan kemampuan seseorang untuk mencapai tujuan yang dikehendaki. Problematika yang dihadapi saat ini adalah tentu tiap relawan memiliki potensi dan kemampuan yang berbeda, sebagian akan lebih baik dalam bidang tertentu daripada yang lain, begitu pula sebagian yang lain. Penyebab dari adanya perbedaan kemampuan relawan karena perbedaan pengalaman menjadi relawan yang berbeda. Penelitian ini bertujuan untuk mengetahui kesiapan relawan, baik secara fisik, mental, maupun sosial dalam menghadapi fenomena yang terjadi di masyarakat khususnya dalam hal kebencanaan maupun sosial. Kesiapan relawan dalam mengadapi proses pengembangan kapasitas untuk menghadapi fenomena alam dan sosial yang akan terkait dengan persiapan fisik, mental, dan sosial dirinya selama menjalani masa pembinaan pengembangan kapasitas di lembaga organisasi pelayanan sosial Palang Merah Indonesia (PMI). Subyek penelitian adalah relawan yang sedang menjalani proses pembinaan. Metode yang digunakan dala penelitian ini adalah metode penelitian deskriptif dengan pendekatan kualitatif. Data primer dan sekunder diperoleh dari hasil penelaahan hasil studi kepustakaan. Hasil penelitian menunjukan bahwa akibat dari rendahnya kesiapan relawan dalam menghadapi fenomena alam dan sosial. Kesiapan relawan dapat ditinjau berdasarkan kesiapan fisik, mental, dan sosial. Rendahnya kesiapan relawan disebabkan oleh rendahnya bekal keterampilan relawan disebabkan karena dari berbagai latar belakang.
\end{abstract}

ABSTRACT Currently, capacity development is an important part in many aspects of life. In the daily life of capacity development was carried out by education both formal and informal. Volunteer capacity development is a process that can increase a person's ability to achieve the desired goals. Problems faced today is certainly every volunteer has the potential and capabilities are different, some are better in certain areas than others, so were some others. Problems faced today is certainly every volunteer has the potential and capabilities are different, some are better in certain areas than others, so were some others. The cause of the existence of differences in the ability of volunteers due to differences of different volunteering experience. This research aims to know the readiness of volunteers, both physical, mental, and social events in the face of phenomena that occur in the community especially in terms of both social disaster. Playing the readiness of the volunteers in the process of developing the capacity to deal with natural and social phenomena that would be associated with physical preparation, mental, and social coaching him during a period of capacity building in institutions of social service organizations Red Cross Indonesia. Subjects were volunteers who are undergoing the process of coaching. The method used dala this research is descriptive method with qualitative approach. Primary and secondary data obtained from the review of the results of the study of literature. The results showed that the effect of lower readiness of the volunteer 
in the face of natural and social phenomena. Readiness volunteers can be evaluated based on physical readiness, mental, and social. The low readiness of volunteers due to lower supplies due to the skills of volunteers from various backgrounds .

\section{PENDAHULUAN}

Perkembangan jaman yang semakin modern terutama pada era globalisasi seperti sekarang ini menuntut adanya sumber daya manusia yang berkualitas tinggi. Peningkatan kualitas sumber daya manusia merupakan persyaratan mutlak untuk mencapai tujuan pembangunan.

Setiap organisasi baik organisasi perusahaan, organisasi pemerintah maupun organisasi sosial mempunyai aktifitas yang dapat dicapai melalui pelaksanaan pekerjaan di bidang tertentu, dengan menggunakan sumber daya yang ada didalam organisasi tersebut, termasuk sumber daya manusia. Organisasi berupa wadah yang diarahkan pada tujuan, sengaja dirancang sebagai struktur dan sistem kegiatan yang terkoordinasi, dan terkait dengan lingkungan eksternal. Munculnya organisasi pelayanan sosial yang diselenggarakan oleh badan pelayanan sosial (human services organizations) dan meningkatnya jumlah organisasi pelayanan sosial menunjukan adanya upaya kepedulian terhadap masyarakat yang mengalami masalah dan memerlukan bantuan.

Secara umum konsep capacity building dapat dimaknai sebagai proses membangin kapasitas individu, kelompok atau organisasi. Pengembangan kapasitas juga dapat diartikan sebagai upaya memperkuat kapasitas individu, kelompok atau organisasi yang dicerminkan melalui pengembangan kemampuan, keterampilan, potensi, dan bakat serta penguasaan kompetensi-kompetensi sehingga individu, kelompok atau organisasi dapat bertahan dan mampu mengatasi tantangan perubahan yang terjadi secara cepat dan tidak terduga.

Organisasi Palang Merah Indonesia (PMI) merupakan organisasi yang bergerak dalam bidang jasa sosial kemanusiaan, membantu korban bencana alam serta pelayanan kesehatan lainnya yang berpegang pada prinsip-prinsip kepalangmerahan dalam menjalankan tugas dan fungsinya. Pendidikan dan pelatihan pertolongan Pertama berbasis masyarakat atau Community Based First Aid (CBFA). PMI berada dalam gerak pembangunan nasional, PMI tidak terlepas dari tugas-tugas yang telah ditentukan seperti penyelenggaraan transfusi darah, pendidikan dan pelatihan, pembinaan terhadap generasi muda Palang Merah.

Untuk dapat melaksanakan tugas-tugas tersebut dengan hasil yang lebih baik diperlukan pembenahan organisasi dalam segala aspek salah satunya pengembangan Sumber Daya Manusia (SDM) terhadap karyawan/relawan, dengan memberi pendidikan dan pelatihan yang bersifat dasar/lanjutan kepada para karyawan/relawan yang bertugas di kantor ataupun lapangan sehingga lebih profesional dalam pemberian bantuan kepada masyarakat yang terkena musibah.

Program pendidikan dan pelatihan merupakan kebutuhan PMI sebab diharapakan dengan adanya program pendidikan dan pelatihan selain dapat meningkatkan kemampuan SDM juga diharapkan dapat menambah semangat kerja yang tinggi guna meningkatkan prestasi kerja. Berbagai pendidikan dan pelatihan terbukti berdampak positif terhadap perbaikan kapasitas karyawan/relawan, mengurangi kesalahan dalam pemberian bantuan, mengikuti prosedur yang sesuai prinsip-prinsip kepalang merahan dan kemanusiaan. Karyawan/relawan tidak lagi merasa panik, canggung ketika dihadapkan dengan situasi bencana ataupun konflik sebab mereka telah memiliki modal dan pengetahuan menyangkut apa yang harus dilakukan, sebab karyawan/relawan PMI Cabang Cibinong 
perlu mendapat pendidikan dan pelatihan secara berkesinambungan.

\section{TELAAH PUSTAKA}

Pengembangan Kapasitas

Kata kapasitas sering digunakan ketika kita berbicara tentang peningkatan kemampuan seseorang, ketika kita memperoleh sertifikasi, mengikuti pelatihan atau mengikuti pendidikan. Dalam pengertian yang lebih luas, tidak hanya perihal kemampuan organisasi untuk mencapai misinya secara efektif dan kemampuan mempertahankan kelangsungan hidupnya dalam jangka panjang. pembangunan masyarakat, namun kapasitas berkaitan dengan keterampilan dan kemampuan individu dalam meningkatkan kemampuanya untuk keberfungsian sosialnya.

United Nation Development Program (UNDP) mendefinisikan pengembangan kapasitas sebagai suatu proses yang dialami oleh individu, kelompok, organisasi, lembaga dan masyarakat untuk meningkatkan kemampuan mereka agar dapat: 1) melaksanakan fungsifungsi essensial, memecahkan masalah, menetapkan dan mencapai tujuan, dan 2) mengerti dan menangani kebutuhan pengembangan diri mereka dalam suatu lingkungan yang lebih luas secara berkelanjutan.

(Skidmore 1995:269). Pengembangan kapasitas adalah penting karena dapat membantu pekerja dalam meningkatkan pengetahuan dan pemahaman tentang tingkah laku manusia dan hubungan sosial yang menaruh mereka pada posisi yang lebih baik lagi untuk membantu klien, Pengembangan kapasitas menjadi suatu keniscayaan bagi organisasi, karena penempatan karyawan/relawan secara langsung dalam pekerjaan tidak menjamin mereka akan berhasil.

Hal ini dapat diasumsikan bahwa pengembangan sangat penting untuk bekerja lebih menguasai dan lebih baik terhadap pekerjaan yang dijabat atau akan dijabat kedepan. Dengan harapan setelah dilatih dapat menguasai pekerjaannya dan pengembangan lebih jauh untuk menyiapkan tanggung jawab mereka di masa depan.

\section{Bentuk Pengembangan Kapasitas}

Dalam kehidupan sehari-hari pengembangan kapasitas misalnya dilaksanakan dengan pendidikan, baik secara formal maupun informal. Begitu juga kegiatan atau programprogram yang dirancang sebuah organisasi, pelatihan merupakan bagian dari kegiatan pengembangan kapasitas sumber daya manusia. Di dalam organisasi misalnya melalui pelatihan-pelatihan sumberdaya manusia dan pengembangan dari sisi sistem manajerial.

Menurut Harvey Weiner (dalam buku Rex A. Skidmore, Social Work Administration Dynamic Management and Human Relationship, 1983) pengembangan kapasitas terkait dengan manusia dan juga sistem yang ada di sekitarnya, ada 15 bentuk metode pengembangan kapasitas yaitu:

1.Perkuliahan (Lectures)

2.Studi Kasus (Case Presentations)

3.Bermain Peran (Role Playing)

4.Pengembangan Diri (Self-development Programs)

\section{Secara Grup (Group Work)}

6.Permainan Pelatihan (Game Exercises)

7.Fasilitas Perpustakaan (Library Facilities)

8.Melanjutkan Pendidikan (Continuing Education)

9.Pertukaran (Exchange)

10.Pembelajaran yang Efektif (Effective Learning)

11.Tujuan Spesifik (Specific Objective)

12.Pra-asesmen (Preassesment)

13.Perencanaan (Planning)

14.Belajar dari Pengalaman (Learning Experience) 


\section{Evaluasi (Evaluation)}

Dengan mengikuti kegiatan pengembangan maka memperoleh tambahan keterampilan dan pengetahuan baru yang bermanfaat bagi pelaksanaan setiap kegiatan karyawan/relawan, juga manfaatnya semakin besarnya rasa komitmen karyawan/relawan terhadap organisasi akan memberikan dampak terhadap adanya pengurangan tingkat turn over absensi. Dengan demikian juga berarti meningkatkan produktivitas di organisasi tersebut.

\section{Faktor-Faktor yang Mempengaruhi Pengembangan Kapasitas}

Menurut (Riyadi,2003) dalam sebuah artikel secara khusus menyampaikan bahwa faktorfaktor signifikan yang mempengaruhi pembangunan kapasitas meliputi 5 (lima) hal pokok yaitu.

\section{a. Komitmen bersama (Collective commitments)}

Menurut (Milen,2004,h.17) penguatan kapasitas membutuhkan waktu lama dan memerlukan komitmen jangka panjang dan semua pihak yang terlibat. Collective Commitments merupakan modal dasar yang harus terus-menerus ditumbuhkembangkan dan dipelihara secara baik. Pengaruh komitmen bersama sangat besar, karena faktor ini menjadi dasar dari seluruh rancangan kegiatan dan tujuan yang akan dicapai bersama.

b. Kepemimpinan yang kondusif (condusiv Leadership)

Menurut (Rivai dan Mulyadi,2009,h.165) kepemimpinan yang dinamis yang membuka kesempatan yang luas bagi setiap elemen organisasi untuk menyelenggarakan pengembangan kapasitas. Dengan kepemimpinan yang kondusif seperti ini, maka akan menjadi alat pemicu untuk setiap elemen dalam mengembangkan kapasitasnya.

c. Peningkatan Kekuatan dan Kelemahan yang Dimiliki
Mengidentifikasi kekuatan dan kelemahan agar dapat disusun program pengembangan kapasitas yang baik. Dengan adanya pengakuan dari personal dan lembaga tentang kelemahan dan kekuatan yang dimiliki dari kapasitas yang tersedia. Maka kelemahan yang dimiliki oleh suatu organisasi dapat cepat diperbaiki dan kekuatan yang dimiliki organisasi tetap dijaga dan dipelihara.

Komponen Keberhasilan Pengembangan Kapasitas

\section{A. Tenaga Pendidik (Pelatih)}

Tenaga pendidik (pelatih) merupakan salah satu faktor penting yang harus diperhatikan dalam pelaksanaanya. Tenaga pendidik atau pelatih yang mengajar hendaknya memiliki kualifikasi yang dipersyaratkan, yaitu memiliki pengetahuan, keterampilan, dan sikap tentang materi yang akan diajarkan/dilatihkan, dan memahami karakteristik peserta

Pelatih juga berperan penting dalam menerapkan metode yang tepat agar potensi peserta dapat berkembang dengan cepat. Pelatih harus benar-benar memahami kedudukan metode sebagai alat motivasi ekstrinsik dalam kegiatan belajar mengajar. Motivasi ekstrinsik menurut Sardiman A.M (90:1988) adalah motif-motof yang aktif dan berfungsi sebagai perangsang atau stimulus dari luar sehingga dapat membangkitkan kegiatan belajar mengajar.

\section{B. Input Pesera Didik}

Kemampuan awal dan karakteristik peserta menjadi acuan utama dalam mengembangkan kurikulum dan bahan ajar serta penyelenggaraan pengembangan kapasitas relawan PMI. Menurut Suharsismi Arikunto (12:1986), peserta didik adalah siapa saja yang terdaftar sebagai objek didik disuatu lembaga pendidikan. Sementara UU Sisdiknas menjelaskan bahwa peserta didik adalah anggota masyarakat yang berusaha mengembangkan potensi dirinya melalui proses pembelajaran yang tersedia pada jalur, jenjang, dan jenis pendidikan tertentu. 


\section{Lingkungan dan Penyelenggaraan}

Faktor pendukung yang berkaitan dengan terciptanya lingkungan kesukarelaan dalam pelayanan sosial salah satunya yaitu pemerintah. Pemerintah juga berperan penting dalam menentukan pelaksanaan pengembangan kapasitas sumber daya relawan. Pemerintah dituntut membantu dalam merumuskan kebijakan-kebijakan terkait internal organisasi, mengingkatkan kualitas pelatih dan tenaga didik melalui pelatihan pada bidang filantropy (kedermawanan), voluntary (kesukarelaan), dan humanity (kemanusiaan). Dengan memberikan bantuan berupa anggaran khusus dalam pengadaan media, alat, dan sarana yang dibutuhkan selama program peningkatkan kapasitas baik anggota maupun relawan itu sendiri yang nantinya bermanfaat untuk masyarakat luas

\section{Sarana dan Prasarana}

Sarana dan prasarana adalah faktor lain yang harus diperhatikan dalam pelaksanaan pendidikan pengembangan kapasitas. Sebagai salah faktor yang harus diperhatikan, tersedianya sarana dan prasarana tidak serta merta mudah diperoleh dengan mudah, tetapi dibutuhkan kerja keras dari pemerhati (pemerintah) untuk mengupayakan fasilitas pendukung yang mendorong peningkatan kualitas relawan dalam memberikan pelayanan sosial.

\section{E. Evaluasi Pembelajaran}

Evaluasi adalah suatu tindakan atau proses untuk menentukan nilai dari sesuatu (Syaiful Bahri, 57:1996). Evaluasi pembelajaran bagi peserta didik berarti kegiatan menilai proses dan hasil belajar, baik yang berupa kulikurel, ko-kurikuler, maupun ekstrakulikuler. Penilaian hasil belajar bertujuan untuk melihat kemajuan dan prestasi belajar peserta didik dalam hal penguasaan materi pengajaran yang telah dipeljarinya sesuai dengan tujuan-tujuan yang telah ditetapkan.

Proses evaluasi digunakan untuk memberikan suatu nilai kepada objek yang dievaluasi sehingga manfaat atau nilai instrinsiknya dapat disampaikan kepada orang lain. Menurut Arif S. Sadiman (182:2006) ada dua macam evaluasi multimedia yang berkaitan dengan kebutuhan anak berkebutuhan khusus, yaitu evaluasi formatif dan evaluasi sumatif. Evalusi formatif adalah proses mengumpulkan bahanbahan pembelajaran (termasuk media), sementara evaluasi sumatif adalah menentukan apakah media yang dibuat dapat digunakan dalam situasi tertentu dan untuk menentukan efektivitas media tersebut.

\section{Konsep Relawan}

Persoalan relawan pada suatu organisasi pelayanan sosial merupakan persoalan yang memerlukan perhatian tersendiri, khususnya berkaitan dengan makin marak bermunculan berbagai organisasi pelayanan sosial. Posisi para relawan pada organisasi pelayanan manusia (sosial) merupakan bagian yang tidak terpisahkan dari sumber daya yang dimiliki oleh suatu organisasi. Relawan bekerja tanpa imbalan gaji dan bersedia memberikan waktu dan energinya.

Dalam buku (Tracy Daniel Connors 1999:37, The Volunteer Management Handbook) mendefinisikan relawan sebagai berikut:

"Volunteering is generally considered an altruistic activity and is intended to promote goodness or improve human quality of life. In return, this activity can produce a feeling of self-worth and respect. There is no financial gain involved for the individual. Volunteering is also renowned for skill development, socialization, and fun. Volunteering may have positive benefits for the volunteer as well as for the person or community served. It is also intended to make contacts for possible employment. It is helping, assisting, or serving another person or persons without pay. Many volunteers are specifically trained in the areas they work, such as medicine, education, or emergency rescue. Others serve on an asneeded basis, such as in response to a natural disaster."

Makna yang diperoleh relawan adalah sebagai peluang untuk berbuat baik di jalan Allah, 
sebagai aksi cepat tanggap kepada orang yang membutuhkan sebagai bentuk aplikasi dari ilmu yang yang didapat, kesungguhan niat dalam berbuat hal yang baik, bentuk pengorbanan tanpa mengharapkan apapun.

\section{Organisasi Pelayanan Sosial}

Istilah umum yang digunakan sebagai suatu ciri dari organisasi pekerjaan sosial dan kesejahteraan sosial adalah organisasi pelayanan manusia/sosial. Penggunaan istilah ini menunjukkan bahwa terdapat organisasi yang terlibat dalam kagiatan yang berkaitan dengan suatu isu masalah. Hasenfeld dalam (Jones and May, 1992: 83) mendefinisikan organisasi pelayanan manusia sebagai berikut:

“... that set of organizations whose principal function is to protect, maintain, or enhance the personal well-being of individuals by defining, shaping, or altering their personal attributes ... these organizations are distinguished from other bureaucracies by two key characteristics. First, they work with and on people whose attributes they attempt to shape. People are in a sense their 'raw material'. Second, they are mandated-and thus justify existence - to protect and promote the welfare of the people they serve "

(“... Bahwa set organisasi yang fungsi utamanya adalah untuk melindungi, memelihara, atau meningkatkan kesejahteraan pribadi dari seorang individu dengan mendefiniskan, membentuk, atau mengubah stribut/sifat pribadi mereka ... organisasi-organisasi ini dibedakan dari birokrasi lainnya dengan dua kunci karakteristik. Pertama, mereka bekerja dengan dan pada orang-orang yang berusaha untuk membentuk atribut/sifat mereka. Orangorang dalam arti mereka merupakan "raw material". Kedua, mereka diberi mandat dengan demikian membenarkan keberadaan mereka untuk melindungi dan meningkatkan kesejahteraan orang yang mereka layani.)

Jadi dapat disimpulkan bahwa organisasi pelayanan manusia merupakan suatu organisasi dimana wadah memperoleh sumber-sumber, pelayanan dan kesempatan yang mereka perlukan untuk memenuhi berbagai kebutuhan hidupnya, menghilangkan ketelantaran serta untuk mewujudkan aspirasinya. Hal ini juga berkaitan dengan kesejahteraan yang menyeluruh tertama berkaitan dengan kebutuhan manusia secara sosial

Organisasi sosial dibagi menjadi beberapa jenis sesuai dengan bidang pelayanan yang diberikan oleh setiap organisasi/lembaga. Pelayanan-pelayanan yang diberikan oleh organisasi pelayanan manusia/sosial disebut pelayanan sosial. Friedlander dalam (Santoso, 2002: 11-12) mengemukakan beberapa jenis pelayanan sosial yang ditangani oleh organisasi manusia/sosial sebagai berikut :

a. Bantuan sosial

b. Asuransi sosial

c. Pelayanan kesejahteraan keluarga

d. Pelayanan kesejahteraan anak

e. Pelayanan kesehatan dan pengobatan

f. Pelayanan kesejahteraan jiwa

g. Pelayanan koreksional

h. Pelayanan kesejahteraan pemuda pengisian waktu luang

i. Pelayanan kesejahteraan bagi veteran

j. Pelayanan ketenagakerjaan

k. Pelayanan bidang perumahan

1. Pelayanan sosial internasional

m. Pelayanan kesejahteraan sosial masyarakat

Dari berbagai pelayanan sosial yang ada, pelayanan kesejahteraan sosial masyarakat merupakan pelayanan yang dilakukan dalam suatu komunitas atau masyarakat. 


\section{DAFTAR PUSTAKA}

Artyawan, Adetyo, Januari 2013, "Pengaruh Soetarso, (1997) , Kesejahteraan Sosial, Pelayanan Sosial, dan Kesejahteraan Sosial, Bandung, STKS.

Kettner, Petter, Human Service Organizations. US States of America. Allyn \& Bacon

Mark, Michael \& Wearing, Michael. 2007. Organisations and Management in Social Work. London : Sage Publications.

Skidmore, Rex A., 1995. Social Work Administration, Dinamic Management and Human Relationships. 3rd Ed. Allyn \& Bacon.

Suparlan, YB. Drs 1990. Kamus Istilah Pekerjaan Sosial, Yogyakarta: Penerbit Kanisius. Hal 41
Suharto, Edi dkk. 2011. Pendidikan dan Praktik Pekerja Sosial di Indonesia dan Malaysia. Yogyakarta: Penerbit Samudra Biru.

Sukoco, Dwi heru.1991. Profesi Pekerjaan Sosial dan Proses Pertolongannya, Bandung : Koperasi Mahasiswa Sekolah Tinggi Kesejahteraan Sosial.

Wibhawa Budhi, Raharjo. T. Santoso, \& Budiari Meilany. 2010. Dasar-Dasar Pekerjaan Sosial. Bandung:Widya Padjadjaran.

Zastrow, Charles H. 2006. Social Work with Groups: A Comprehensive Workbook, USA. Hal 36-8

http://kesos.unpad.ac.id/?p=409 